\title{
Color stability and surface roughness of artificial teeth brushed with an experimental Ricinus communis toothpaste
}

\author{
Lourenço de Moraes Rego Roselino ${ }^{1}$, Carla Cecília Alandia-Román'1, Vanessa María Fagundes Leite ${ }^{1}$, \\ Cláudia Helena Silva-Lovato ${ }^{1}$, Fernanda de Carvalho Panzeri Pires-de-Souza ${ }^{1}$
}

1 Universidade de São Paulo - USP, Ribeirão Preto School of Dentistry, Department of Dental Materials and Prosthodontics, Ribeirao Preto, SP, Brazil

\begin{abstract}
Aim: To evaluate, in vitro, the effect of brushing with a Ricinus communis-based experimental toothpaste on color stability and surface roughness of artificial teeth. Methods: Ninety artificial teeth (maxillary central incisors) in different shades, light and dark (NatusDent Triple Pressing, Dentbras) were used. Initial color (Spectrophotometer Easyshade, VITA) and surface roughness (Rugosimeter Surfcorder SE 1700, Kosakalab) readouts were performed. After baseline measurements, samples were assigned to 10 groups $(n=9)$ according to the artificial tooth shade and type of toothpaste used during the mechanical brushing test (Pepsodent, MAVTEC): Sorriso Dentes Brancos - SDB, Colgate Luminous White - CLW (Colgate-Palmolive), Close up White Now - CWN (Unilever), Trihydral - THL (Perland Pharmacos) and Ricinus communis - RCE (Experimental). After 29,200 cycles of brushing, corresponding to 2 years of brushing by a healthy individual, new color and roughness readouts of the specimens were performed. Data (before and after the tests) were statistically analyzed (2-way repeated measures ANOVA, Tukey, $p<0.05)$. Results: RCE toothpaste produced the greatest color stability for dark tooth shade and the second best color stability for light tooth shade. For surface roughness alteration, there was no difference $(p>0.05)$ for any tested toothpaste regardless of tooth shade. Conclusions: The experimental Ricinus communis toothpaste did not cause color and surface roughness alteration in the artificial teeth, and it may be considered a suitable option for denture cleaning.
\end{abstract}

Keywords: oral hygiene; toothpastes; castor oil; color.

\section{Introduction}

With the increasing life expectancy and consequent ageing of the worldwide population, wear and stain of artificial teeth have become more and more common, jeopardizing the aesthetic appearance of removable prosthesis, since artificial teeth are a significant factor for the aesthetic outcome. One of the most important cautions that the edentulous patients must have is the maintenance of adequate complete denture hygiene ${ }^{1}$, which is important to increase denture longevity ${ }^{2}$.

Methacrylate-based resins (acrylic resin) are the most commonly used material for artificial denture teeth in prosthetic dentistry, due to many advantages, such as the chemical bond to denture base, lower susceptibility to fracture, easy handling and limited biofilm accumulation ${ }^{3-4}$. However, one disadvantage is the increased wear and discoloration after certain time of use $^{1}$. To overcome this shortcoming, highly resistant resin teeth with an interpenetrating polymer network was developed 
increasing the amount of cross-linked agents or blending special polymers and co-polymers. Improved mechanical and physical properties have been achieved ${ }^{5-6}$, but susceptibility to staining and wear ${ }^{7}$ still remains.

Different from patients with remaining natural teeth, edentulous patients have no periodontal ligament receptors that regulate occlusal forces ${ }^{8}$. This is an aggravating factor for artificial teeth wear, because despite the reduced maximum occlusal force when compared with natural teeth, edentulous patients have a higher masticatory frequency ${ }^{9}$.

Cleaning methods for dentures include daily brushing and immersion in denture cleaners ${ }^{10}$. There is a large number of chemical dental cleansers for immersion, containig substances like alkaline peroxides, alkaline hypochlorites, acids, enzymes and disinfectants, which are widely used for denture cleaning due to their bactericidal and fungicidal properties ${ }^{11}$. However, some of these solutions may cause alterations in the physical and mechanical properties of denture base resin ${ }^{12}$ and artificial teeth ${ }^{13}$ due to the penetration of these agents into the material.

Brushing is the most commonly used method for denture hygiene, since it is a simple, inexpensive and effective hygiene method ${ }^{14}$. Furthermore, brushing has the same efficiency as a chemical method for biofilm removal ${ }^{14}$. The brushing method is combined with the use of toothpastes, which have a complex composition including water, detergents, flavoring, abrasive and therapeutic agents.

Due to its characteristics, many studies have shown that brushing is the cleaning method of choice for complete dentures wearers ${ }^{15}$. However, if improperly used, the acrylic resin may become rough ${ }^{16}$, leading to microorganism and organic matter retention ${ }^{17}$, reducing cleaning and increasing stain.

The addition of antimicrobial agents facilitates the cleaning and sanitizing procedures for denture users ${ }^{18}$. Many plants are known to possess antimicrobial properties, and several innovative attempts have been made to incorporate them into daily oral hygiene products. Ricinus communis, also known as castor plant, is found in tropical climates, as in Brazil ${ }^{19}$. Its oil has been used to produce detergent agents and could be an alternative for denture cleaning, as it causes cell destruction by breaking the sugar leakage of the cellular wall of pathogenic microorganisms ${ }^{20}$. Recently, a study has demonstrated the antimicrobial potential of a Ricinus communis-based experimental dentifrice for denture hygiene which seems to be related to the presence of a strong surfactant ${ }^{18}$.

Due to the constant pursuit of aesthetics, and the importance of durability, staining resistance and color-stability of denture teeth ${ }^{21}$, the objective of this study was to evaluate in vitro the effect of brushing with an experimental Ricinus communis-based toothpaste on color stability and surface roughness of artificial teeth. The tested null hypothesis was that the experimental dentifrice will not produce color change and surface roughness in the artificial teeth.

\section{Material and methods}

The present study used 90 artificial teeth (maxillary central incisors) in different shades, light (60) and dark (69) (NatusDent Tripla Prensagem - Dentbras Ind, Pirassununga, $\mathrm{SP}$, Brazil). Teeth were embedded in PVC cylinders $(1 \mathrm{~cm}$ high $\times 2 \mathrm{~cm}$ diameter) with self-cured acrylic resin (VipiFlash, Ltda. Pirassununga, SP, Brazil) using a paralellometer to stabilize their buccal surface facing upwards.

Initial color (Spectrophotometer Easyshade, VITA Zahnfabrik, BadSäckingen, Germany) and surface roughness (Rugosimeter Surfcorder SE 1700, Kosakalab, Tokyo, Japan) readouts of the specimens were taken. For color readouts, the observation pattern followed the CIE L*a*b* system (Comission Internationale de I'E' clairage) which simulates a measurement of 45/0 geometry, D65 standard illuminant, and observer pattern of $2^{\circ}$. The specular component was excluded in order to prevent interference by surface brightness. The $\mathrm{L}^{*} \mathrm{a}^{*} \mathrm{~b}^{*}$ system consists of two axes, a* and $\mathrm{b}^{*}$, at right angle and represent the dimension of tonality or color. The third axis is luminosity $\mathrm{L}^{*}$, perpendicular to the $a^{*} b^{*}$ plane.

For color readings, the digital tip of the device $(6 \mathrm{~mm}$ diameter) was positioned perpendicular to the buccal surface of artificial teeth and three measurements were taken; the mean of them was considered the baseline color value.

For surface roughness measurements, a needle with a very fine diamond at its tip was driven at constant speed over a distance of $4.8 \mathrm{~mm}$ with a $0.8 \mathrm{~mm}$ cut-off and a 0.25 $\mathrm{mm} / \mathrm{s}$ speed. Three readouts were taken at different sites on the sample surface to obtain the mean roughness $\left(\mathrm{R}_{\mathrm{a}}\right)$.

After color and roughness baseline readings, samples were assigned to 10 groups $(n=9)$ according to the shade of the artificial tooth and type of toothpaste used during the mechanical brushing test (Table 1).

Mechanical brushing (Pepsodent, MAVTEC - Com Parts, Acc., and Serv. Ltda. ME, Ribeirão Preto, SP, Brazil) was performed with soft toothbrushes (Tek, Johnson \& Johnson Ind. Com Ltda., São José dos Campos, SP, Brazil) - one per specimen. The toothbrush heads were separed from stem and then fitted into the clamp of the equipment. Each brush/ clamp set resulted in a final weight of $200 \mathrm{~g}$

Each specimen was fitted into a central circular hole (of equal dimensions) of a plexiglass slide (Acrilpress Artefacts Ltda., Ribeirão Preto, SP, Brazil) to allow adaptation and fixation during mechanical brushing $($ course $=3.8 \mathrm{~cm}$; speed $=356 \mathrm{rpm}$ ) with toothpaste diluted in distilled water $(1: 1)$.

Specimens were subjected to 29,200 cycles of mechanical brushing, corresponding to 2 years of exposure to brushing by a healthy individual ${ }^{22}$. After brushing, new color and roughness readouts were performed. Color alteration $(\Delta E)$ was calculated according to the formula:

$\Delta E=\left[\left(\text { (" } \mathrm{L}^{*}\right)^{2}+\left(\text { " } \mathrm{a}^{*}\right)^{2}\left(\text { " } \mathrm{b}^{*}\right)^{2}\right]^{1 / 2}$

where $\Delta E=$ color alteration;

$\Delta L=$ lightness difference $\left(L^{*}\right)$, so that the greater $L^{*}$ values, the higher the brightness of the sample;

$\Delta a=$ axis $a^{*}$ difference; so that positive values for $\Delta a$ means redder samples and negative values, greener;

$\Delta b=$ axis $b^{*}$ difference; so that positive values for $\Delta b$ mean yellower samples and negative values bluer, being: 
Table 1. Groups formed according to tooth shade and dentifrice used in the study.

\begin{tabular}{|c|c|c|c|}
\hline GROUPS & SHADES & TOOTHPASTE & COMPOSITION \\
\hline $\begin{array}{l}1 \\
2\end{array}$ & $\begin{array}{l}\text { Light } \\
\text { Dark }\end{array}$ & $\begin{array}{l}\text { Sorriso Dentes Brancos } \\
\text { (Palmolive Ltda, São } \\
\text { Bernardo do Campo, SP, } \\
\text { Brazil) }\end{array}$ & $\begin{array}{c}\text { Calcium carbonate, Water, Glycerin, Sodium lauryl sulfate, sodium } \\
\text { monofluorophosphate (1450 ppm fluoride), cellulose gum, tetrasodium pyrophosphate, } \\
\text { sodium bicarbonate, benzyl alcohol, sodium saccharin, sodium hydroxide and } \\
\text { limonene. }\end{array}$ \\
\hline $\begin{array}{l}3 \\
4\end{array}$ & $\begin{array}{l}\text { Light } \\
\text { Dark }\end{array}$ & $\begin{array}{l}\text { Colgate Luminous White } \\
\text { (Palmolive Ltda, São } \\
\text { Bernardo do Campo, SP, } \\
\text { Brazil }\end{array}$ & $\begin{array}{l}\text { Water, hydrated silica, glycerin, pentasodium triphosphate, PEG-12, Tetrapotassium } \\
\text { Pyrophosphate, sodium lauryl sulfate, cellulose gum, polyethylene, cocamidopropyl } \\
\text { betaine, xanthan gum, sodium saccharin, sodium hydroxide, titanium dioxide, D \& C } \\
\text { blue } 1 \text { aluminum lake (Cl 42090) and sodium fluoride (1100 ppm fluoride). }\end{array}$ \\
\hline $\begin{array}{l}5 \\
6\end{array}$ & $\begin{array}{l}\text { Light } \\
\text { Dark }\end{array}$ & $\begin{array}{l}\text { Close up White Now } \\
\text { (Unilever Ltda, Ipojuca, PE, } \\
\text { Brazil) }\end{array}$ & $\begin{array}{l}\text { Sorbitol, water, silica, PEG-32, sodium lauryl sulfate, cellulose gum, sodium fluoride } \\
\text { (1450 ppm), Saccharin sodium, PVM / MA copolymer, trisodium phosphate, Mica, Cl } \\
74160 \text { and limonene. }\end{array}$ \\
\hline $\begin{array}{l}7 \\
8\end{array}$ & $\begin{array}{l}\text { Light } \\
\text { Dark }\end{array}$ & $\begin{array}{l}\text { Trihydral (Perland } \\
\text { Pharmacos Ltda, Cornélio } \\
\text { Procopio, PR, Brazil) }\end{array}$ & $\begin{array}{l}\text { Sodium fluoride (1500 ppm), sodium monofluorophosphate, } 0.2 \% \text { Chloramine-T, calcium } \\
\text { carbonate, propylene glycol, sorbitol, hydroxyethylcellulose, tetrasodium } \\
\text { pyrophosphate, sodium laurylsulfate, Decyl polyglucose, Metilpabenzeno and Water. }\end{array}$ \\
\hline $\begin{array}{c}9 \\
10\end{array}$ & $\begin{array}{l}\text { Light } \\
\text { Dark }\end{array}$ & $\begin{array}{c}\text { Ricinus communis } \\
\text { (Experimental) }\end{array}$ & $\begin{array}{l}\text { Hydroxyethylcellulose, glycerine, EDTA, sodium saccharin, ricinoleic acid ester, Silica } \\
\text { (sident 9) Silica (sident 22S), titanium dioxide, methylparaben, sodium lauryl sulfate } \\
\text { and water. }\end{array}$ \\
\hline
\end{tabular}

$\Delta L=L_{\mathrm{f}}-L_{\mathrm{i}}$

$\Delta a=a_{\mathrm{f}}-a_{\mathrm{i}}$

$\Delta b=b_{\mathrm{f}}-b_{\mathrm{i}}$

where $L^{*}, a^{*}{ }_{i}$ e $b^{*}$ are referred to as the initial color measurement and $L^{*}, a^{*}{ }_{\mathrm{f}}$ e $b^{*}{ }_{\mathrm{f}}$ as the final color measurement. Color alteration values greater than 3.3 were considered clinically unacceptable ${ }^{10}$.

Surface roughness alteration $\left(\Delta \mathrm{R}_{\mathrm{a}}\right)$ was calculated according to the formula:

$\Delta \mathrm{R}_{\mathrm{a}}=\mathrm{R}_{\mathrm{af}}-\mathrm{R}_{\mathrm{ai}}$

Where $\mathrm{Ra}_{\mathrm{i}}$ is the initial roughness measurement and $\mathrm{Ra}_{\mathrm{f}}$ the final roughness measurement.

After verifying the normality of the results, the values were analyzed by 2-way repeated measures ANOVA and by the multiple-comparisons Bonferroni test with $95 \%$ significance level.

\section{Results}

The means of color alteration $(\Delta E)$ and surface roughness $\left(\Delta \mathrm{R}_{\mathrm{a}}\right)$ were compared (2-way repeated measures ANOVA, Bonferroni test, $\mathrm{p}<0.05)$, considering Treatments and Tooth shade as variation factors. (Table 2 and 3 respectively).

For light teeth shade, SDB and CLW toothpastes presented greater $(p<0.05)$ color change compared with the other toothpastes, which showed no difference $(p>0.05)$ between them. Regarding dark teeth shade, the greatest color change $(p<0.05)$ occurred after brushing with CLW, a result similar $(\mathrm{p}>0.05)$ to $\mathrm{SDB}$, which showed no difference $(p>0.05)$ compared with other toothpastes. RCE toothpaste produced the greatest color stability for dark teeth shade and the second best color stability for light teeth shade.
Table 2. Means (standard deviation) of color stability $(\Delta E)$ of artificial teeth (light and dark) subjected to mechanical brushing with different toothpastes (2-way ANOVA, Bonferroni test, $\mathrm{p}<0.05)$.

\begin{tabular}{lcc}
\hline Toothpastes & Light Shade (60) & Dark Shade (69) \\
Sorriso Dentes Brancos (SDB) & $2.57(0.93)^{\mathrm{aA}}$ & $1.50(0.43)^{\mathrm{bAB}}$ \\
Colgate Luminous White (CLW) & $2.17(0.60)^{\mathrm{aA}}$ & $2.27(0.62)^{\mathrm{aA}}$ \\
Close up White Now (CWN) & $0.68(0.35)^{\mathrm{aB}}$ & $1.17(0.65)^{\mathrm{aB}}$ \\
Trihydral (THL) & $0.84(0.43)^{\mathrm{aB}}$ & $1.13(0.88)^{\mathrm{aB}}$ \\
Experimental (RCE) & $0.72(0.29)^{\mathrm{aB}}$ & $0.83(0.51)^{\mathrm{aB}}$ \\
\hline
\end{tabular}

Different letters, lowercase in rows and uppercase in columns, indicate statistically significant difference $(p<0.05)$.

Table 3. Means (standard deviation) of surface roughness alteration $\Delta \mathrm{R}_{\mathrm{a}}$ of artificial teeth (light and dark) subjected to mechanical brushing with different dentifrices (2-way ANOVA, Bonferroni test, $\mathrm{p}<0.05)$.

\begin{tabular}{lcl}
\hline Toothpastes & Light Shade & Dark Shade \\
Sorriso Dentes Brancos (SDB) & $0.349(0.32)$ & $0.156(0.46)$ \\
Colgate Luminous White (CLW) & $0.402(0.22)$ & $0.217(0.28)$ \\
Close up White Now (CWN) & $-0.181(0.48)$ & $-0.131(0.35)$ \\
Trihydral (THL) & $-0.134(0.49)$ & $-0.036(0.79)$ \\
Experimental (RCE) & $-0.056(0.38)$ & $-0.286(0.68)$ \\
\hline
\end{tabular}

There was no statistically significant difference among the groups $(p>0.05)$.

When the effect of toothpastes was compared for light and dark teeth shade, only SDB produced significant color change $(p<0.05)$, greater for light teeth shade. There was no statistical significance $(p>0.05)$ for the other comparisons.

The comparison of surface roughness alterations showed 
no significant difference $(p>0.05)$ for any tested toothpaste regardless of tooth shade.

\section{Discussion}

This study evaluated the effect of mechanical brushing $(29,200$ cycles $=2$ years $)$ on the color stability $(\Delta E)$ and surface roughness $\left(\Delta \mathrm{R}_{\mathrm{a}}\right)$ of two shades (60 and 69) of artificial teeth brushed with different toothpastes. The null hypothesis stated that there would be no difference in the studied properties regardless the tested toothpastes. Considering the results, it was possible to accept partially the tested hypothesis, since there was a greater color alteration for teeth brushed with two types of toothpaste (SDB and CLW), this alteration was greater when SDB was used on light tooth shade. However, there was no surface roughness alteration regardless of the tested toothpaste or tooth shades.

When $\Delta E$ was analyzed, light shade samples brushed with RCE (Experimental), CWN and THL toothpastes, showed less color alteration than those brushed with SDB and CLW. The same occurred for dark shade samples, except for those brushed with SDB, which showed a $\Delta E$ similar to the samples brushed with the other toothpastes used in the study.

The color alteration of a material is expressed in units of $\Delta E$, which represent the color change after different treatments. In dental literature, several authors ${ }^{23}$ have used $\Delta E$ values to evaluate the "perceptibility" of color differences. Color difference thresholds constitute the lowest perceptual limit to estimate the maximum number of discernible colors by the human visual system. There are two major thresholds for assessing color differences: perceptible and acceptable ${ }^{24}$, passing from "just noticeable differences" to "color tolerances" 25 . However, it is noteworthy to underline that the criteria of perceptibility adopted by each author are different.

In this study, the threshold used as perceptible was $\Delta \mathrm{E}=2.7^{25}$, above this value, color changes would be considered aesthetically unacceptable. Thus, analyzing the results, it was found that all samples showed acceptable levels of color change, regardless the used type of dentifrice.

The denture teeth used in this study are composed by triple-pressed acrylic layers of PMMA (polymethyl metacrylate) and EDMA (dimethacrylate of polymerized ethylene glycol), which is a cross-linking agent. However, even the more resistant teeth are subject to water sorption, demonstrated by microhardness decrease ${ }^{26}$. The water or aqueous cleansers can act as resin plasticizers, since the small molecules of water diffuse into the polymer mass, causing the relaxation of polymer chains ${ }^{27}$. Thus, when penetrating the artificial tooth, solvents may also be responsible for the color change of teeth. Furthermore, artificial teeth have small amounts of dibenzoyl peroxide, a heat-sensitive initiator added to the polymer, which remains after polymerization and may also alter the material's optical properties ${ }^{28}$.

Even though the color stability may have been compromised by the above-mentioned factors, in this study the teeth showed color changes within the acceptable limits and the experimental Ricinus communis-based dentifrice showed the smallest color change values. This may be justified by the effect of polishing and wear produced by the dentifrice abrasiveness, as evidenced by the negative values found for roughness changes.

Increased values of surface roughness caused by the formation of a Ricinus communis pellicle on the specimen surface have been reported in a previous study ${ }^{12}$ that used Ricinus communis in an experimental immersion cleaning solution. This pellicle was not observed in the present study, since brushing and subsequent polishing of the tooth surface kept teeth free of this pellicle, with non-significant surface roughness alteration, maintaining the color stability.

Besides the polishing effect, the composition of toothpastes may have also contributed to these findings. SDB has calcium carbonate in its composition, unlike the other tested dentifrices, which have silica as abrasive agent. Calcium carbonate has a lower abrasive potential than silica, but this component is not the sole responsible for dentifrice abrasiveness. CLW is more abrasive than SDB as it presents highly abrasive components in its composition, such as tetra potassium pyrophosphate. One could expect higher levels of color alteration because of the dentifrice abrasiveness; however, color changes occurred within the acceptable limits, which might be justified by the presence of a bleaching agent, sodium hydroxide, in the dentifrice composition.

It is important to highlight the research and efforts undertaken worldwide to develop new plant-derived materials. The experimental Resinus communis-based dentifrice produced similar color alteration when compared with most commercial toothpastes, including the specific dentifrice for denture cleaning (Trihydral), and did not increase the surface roughness of teeth. These are important findings for the validation of the new experimental material.

It may be concluded that artificial acrylic resin teeth brushed with the experimental Ricinus communis-based dentifrice did not undergo color or surface roughness alteration, thus the experimental dentifrice may be considered a suitable option for denture cleaning.

\section{Acknowledgements}

The authors would like to thank the São Paulo Research Foundation (Brazil), for their financial support, protocol No. 2012/13342-4. The authors have no conflict of interests to disclose.

\section{References}

1. Andrade IM, Andrade KM, Pisani MX, Silva-Lovato $\mathrm{CH}$, de Souza RF, Paranhos $\mathrm{H}$ de $\mathrm{F}$. Trial of an experimental castor oil solution for cleaning dentures. Braz Dent J. 2014; 25: 43-7.

2. Pisani MX, da Silva CH, Paranhos HF, Souza RF, Macedo AP. Evaluation of experimental cleanser solution of Ricinus communis: effect on soft denture liner properties. Gerodontology. 2012; 29: 179-85.

3. Heintze SD, Zellweger G, Sbicego S, Rousson V, Munoz-Viveros C, Stober T. Wear of two denture teeth materials in vivo - 2-year results. Dent Mater. 2013; 29: e191-204. 
4. Schmid-Schwap M, Rousson V, Vornwagner K, Heintze SD. Wear of two artificial tooth materials in vivo: a 12-month pilot study. J Prosthet Dent. 2009; 102: 104-14.

5. Ayaz EA, Altintas SH, Turgut S. Effects of cigarette smoke and denture cleaners on the surface roughness and color stability of different denture teeth. J Prosthet Dent. 2014; 112: 241-8.

6. Kurtulmus-Yilmaz S, Deniz ST. Evaluation of staining susceptibility of resin artificial teeth and stain removal efficacy of denture cleansers. Acta Odontol Scand. 2014; 72: 811-8.

7. Phunthikaphadr T, Takahashi H, Arksornnukit M. Pressure transmission and distribution under impact load using artificial denture teeth made of different materials. J Prosthet Dent. 2009; 102: 319-27.

8. Alajbeg IZ, Valentic-Peruzovic M, Alajbeg I, Illes D, Celebic A. The influence of dental status on masticatory muscle activity in elderly patients. Int J Prosthodont. 2005; 18: 333-8.

9. Fontijn-Tekamp FA, Slagter AP, Van der Bilt A, Van't Hof MA, Kalk W, Jansen JA. Swallowing thresholds of mandibular implant-retained overdentures with variable portion sizes. Clin Oral Implants Res. 2004; 15: 375-80.

10. Harrison Z, Johnson A, Douglas CW. An in vitro study into the effect of a limited range of denture cleaners on surface roughness and removal of Candida albicans from conventional heat-cured acrylic resin denture base material. J Oral Rehabil. 2004; 31: 460-7.

11. Felipucci DN, Davi LR, Paranhos HF, Bezzon OL, Silva RF, Pagnano VO. Effect of different cleansers on the surface of removable partial denture. Braz Dent J. 2011; 22: 392-7.

12. Pisani MX, da Silva CHL, Paranhos HDO, Souza RF, Macedo AP. The effect of experimental denture cleanser solution ricinus communis on acrylic resin properties. Mater Re. 2010; 13: 369-73.

13. Campanha NH, Pavarina AC, Jorge JH, Vergani $C E$, Machado AL, Giampaolo ET. The effect of long-term disinfection procedures on hardness property of resin denture teeth. Gerodontology. 2012; 29: e571-6.

14. Paranhos HF, Silva-Lovato $\mathrm{CH}$, de Souza RF, Cruz PC, de FreitasPontes KM, Watanabe E, et al. Effect of three methods for cleaning dentures on biofilms formed in vitro on acrylic resin. JProsthodont. 2009; 18: 427-31.

15. Paranhos H de F, Davi LR, Peracini A, Soares RB, Lovato $\mathrm{CH}$, Souza RF. Comparison of physical and mechanical properties of microwavepolymerized acrylic resin after disinfection in sodium hypochlorite solutions. Braz Dent J. 2009; 20: 331-5.

16. Tanoue N, Matsumura $\mathrm{H}$, Atsuta $\mathrm{M}$. Wear and surface roughness of current prosthetic composites after toothbrush/dentifrice abrasion. J Prosthet Dent. 2000; 84: 93-7.

17. Verran J, Jackson S, Coulthwaite L, Scallan A, Loewy Z, Whitehead K. The effect of dentifrice abrasion on denture topography and the subsequent retention of microorganisms on abraded surfaces. J Prosthet Dent. 2014; 112: 1513-22.

18. Leite VM, Pinheiro JB, Pisani MX, Watanabe E, de Souza RF, Paranhos $\mathrm{H}$ de $\mathrm{F}$, et al. In vitro antimicrobial activity of an experimental dentifrice based on Ricinus communis. Braz Dent J. 2014; 25: 191-6.

19. Meneghin MP, Nomelini SM, Sousa-Neto MD, Marchesan MA, Franca SC, dos Santos HS. Morphologic and morphometric analysis of the root canal apical third cleaning after biomechanical preparation using 3.3\% Ricinus communis detergent and $1 \% \mathrm{NaOCl}$ as irrigating solutions. J Appl Oral Sci. 2006; 14: 178-82.

20. Pisani MX, Macedo AP, Paranhos H de F, Silva CH. Effect of experimental Ricinus communis solution for denture cleaning on the properties of acrylic resin teeth. Braz Dent J. 2012; 23: 15-21.

21. Gregorius WC, Kattadiyil MT, Goodacre CJ, Roggenkamp CL, Powers JM, Paravina RD. Effects of ageing and staining on color of acrylic resin denture teeth. J Dent. 2012; 40: e47-54.

22. Wiegand A, Kuhn M, Sener B, Roos M, Attin T. Abrasion of eroded dentin caused by toothpaste slurries of different abrasivity and toothbrushes of different filament diameter. J Dent. 2009; 37: 480-4.
23. Dietschi D, Abdelaziz M, Krejci I, Di Bella E, Ardu S. A novel evaluation method for optical integration of class IV composite restorations. Aust Dent J. 2012; 57: 446-52.

24. Perez $M$ del $M$, Ghinea R, Herrera $L J$, Ionescu AM, Pomares $H$, Pulgar $R$, et al. Dental ceramics: a CIEDE2000 acceptability thresholds for lightness, chroma and hue differences. J Dent. 2011; 39: e37-44.

25. Paravina RD, Ghinea $R$, Herrera $L J$, Bona AD, Igiel $C$, Linninger $M$, et al. Color difference thresholds in dentistry. J Esthet Restor Dent. 2015; 27: S1-9.

26. Pavarina AC, Vergani CE, Machado AL, Giampaolo ET, Teraoka MT. The effect of disinfectant solutions on the hardness of acrylic resin denture teeth. J Oral Rehabil. 2003; 30: 749-52.

27. Braun KO, Mello JA, Rached RN, Del Bel Cury AA. Surface texture and some properties of acrylic resins subjected to chemical polishing. J Oral Rehabil. 2003; 30: 91-8.

28. Assuncao WG, Barao VA, Pita MS, Goiato MC. Effect of polymerization methods and thermal cycling on color stability of acrylic resin denture teeth. J Prosthet Dent. 2009; 102: 385-92. 